\title{
PROSES ELEKTROLISA PADA PROTOTIPE "BAHAN BAKAR AIR" KENDARAAN BERMOTOR DENGAN PENGONTROLAN KUALITAS AIR BERBASIS AVR ATMEGA 8535
}

\author{
Darma Arif Wicaksono' ${ }^{1)}$, Sofi Ariyani ${ }^{1)}$, Sutikno ${ }^{1)}$ \\ 1) Jurusan Teknik Elektro - Universitas Muhammadiyah Jember \\ JL. Karimata No. 49, Jember 68121, Jawa Timur
}

\begin{abstract}
ABSTRAK
Pemanfaatan proses elektrolisa air pada pengembangan penelitian di bidang energi hidrogen saat ini menjadi salah satu alternatif sumber bahan bakar air. Proses pemisahan moelekul air menjadi gas hidrogen dan oksigen menggunakan elektrolisa air, yaitu dengan mengalirkan litrik kepada larutan elektrolit (katalis $\mathrm{NaCl}$ dan air) melalui elektroda alumunium. Bahan bakar berupa gas hidrogen dan oksigen yang dihasilkan oleh proses ini akan digunakan untuk mengurangi konsumsi BBM. Sebanyak 4 tabung digunakan untuk perancangan elektroliser. Larutan maksimal pada masing-masing tabung adalah $500 \mathrm{ml}$ air dan katalis $\mathrm{NaCl} 6$ gram. Kestabilan proses elektrolisa diatur berdasarkan Itensitas air dalam tabung untuk memaksimalkan HHO yang dihasilkan.Dalam hal ini tentu dengan bantuan sensor yang selanjutnya data akan diolah oleh mikrokontroler Atmega8535, yang kemudian ditampilkan di LCD sebgai perintah untuk penggantian air. Bahan bakar air BBA dapat menghasilkan gas HHO dengan adanya arus dari spull motor yang mengalir pada dua eletroda dalam air sehingga terjadi proses elektrolisa dan mengasilkan gas hidrogen HHO yang kemudian masuk keruang bakar mesin dan mengurangi konsumsi BBM.
\end{abstract}

Kata-kata kunci: Bahan bakar air(BBA), mikrokontroller ATmega8535, Sensor LDR, Motor DC, $L C D$, Driver Motor.

\section{PENDAHULUAN}

Seiring meningkatnya harga minyak mentah dunia berpengaruh pada harga bahan bakar minyak (BBM) di dalam negeri. Kenaikan harga BBM akan berakibat pada naiknya harga kebutuhan pokok. Kondisi demikian membuat sebagian orang mencari bahan bakar alternatif selain minyak bumi dan berusaha menghemat konsumsi bahan bakar.

Bahan bakar tambahan kendaraan yang berasal dari gabungan dari gas hidrogen dan oksigen atau disebut HHO adalah pengembangan sumber energi alternatif. Bahan bakar ini dihasilkan dari proses pemisahan moelekul air menjadi hidrogen dan oksigen dengan cara memberikan aliran arus listrik atau dikenal dengan proses elektrolisa. Kemudahan yang ditawarkan oleh sumber energi alternatif ini adalah bahan bakar yang dibutuhkan tidak berasal dari minyak bumi atau gas alam, yakni hanya berasal dari air. Katalis $\mathrm{NaCl}$ (Natrium Clorida) yang dilarutkan dalam air akan mempercepat reaksi dengan bantuan sumber arus yang berasal dari spull sepeda motor, selain itu suhu yang tinggi juga dapat mengurangi jumlah produksi hidrogen dan oksigen. Tetapi, air dalam tabung harus dijaga agar kualitas HHO dapat terjaga dengan baik.

Dengan adanya masalah yang telah dipaparkan, pada penelitian ini akan dilakukan pengaturam kualitas air pada elektroliser untuk mencegah kurang maksimalnya gas yang dihasilkan dan 
pengaturan buka tutup kran secara otomatis. Dalam proyek kali ini guna untuk mendapatkan efisiensi sampai $95 \%$ saya merencanakan memakai 4 buah tabung dengan kapasitas air setiap tabung $500 \mathrm{~mL}$ dan pendeteksi kelayakan air dan mikrokontroler sebagai otak dari sistem ini dan LCD sebagai media pemberitahuan pada pengguna BBA. Manfaat yang diharapkan pada penelitian ini adalah mengatasi kelangkaan BBM dan krisis energi sehingga kita dapat mandiri dalam bidang energi.

\section{DASAR TEORI}

\subsection{Bahan Bakar Air (BBA)}

Bahan bakar air (BBA) adalah bahan bakar yang berasal dari air, dapat berupa hidrogen dan oksigen. Gas HHO adalah kombinasi dari adanya gas hidrogen dan gas oksigen. Dengan proses elektrolisa air unsur HHO akan dapat dihasilkan, dimana partikel/moelekul air terpisah menjadi 2 buah hidrogen dan 1 buah oksigen. BBA dilengkapi dengan sempat tabung yang diisi dengan air. Dalam masing-masing tabung terdapat air yang dicampurkan dengan bahan kimia yang selanjutnya berikan arus listrik sehingga air akan dipisah menjadi gas hidgrogen dan gas oksigen yang dikeluarkan melalui ujung selang yang dihubungkan dengan karburator dan meningkatkan daya ledak yang maksimal sehingga terjadi pembakaran yang sempurna dan membuat mesin lebih bertenaga dan sangat irit BBM.

\subsection{Elektrolisa}

Elektrolisa adalah proses kimiawi dengan mengubah energi listrik menjadi energi kimia. Pemisahan moelekul air menjadi gas hidrogen dan gas oksigen dibantu dengan aliran arus listrik ke elektroda tempat larutan elektrolit (air + katalis). Reaksi yang dihasilkan bukan reaksi spontan atau dapat disebut dengan reaksi redoks yang diakibatkan oleh pengaruh listrik. Proses ini ditemukan pada tahun 1820 oleh Faraday.

\subsection{Larutan Elektrolit}

Larutan elektrolit adalah larutan yang dihasilkan oleh gabungan air dan katalis. Katalis adalah zat yang digunakan untuk mempercepat laju reaksi secara kimiawi yang tidak merubah wujud pada akhir reaksi. Untuk menghasilkan gas HHO pada proses elektrolisa, maka katalis digunakan untuk mempercepat reaksi. Pada penelitian ini katalis yang digunakan adalah Natrium Clorida $(\mathrm{NaCl})$ sebanyak 6 gram yang dilarutkan pada $500 \mathrm{ml}$ air. Potensial elektrode standar yang lebih negatif dari air pada $\mathrm{NaCl}$ membuat larutan ini digunakan karena sehingga tidak akan bereaksi ketika air bereaksi selain itu pertimbangan lain adalah kemudahan akses $\mathrm{NaCl}$. Potensial elektrode standar Natrium (Na) adalah -2,71 dan air $\left(\mathrm{H}_{2} \mathrm{O}\right)$ adalah $-0,83$.

\subsection{Elektroda}

Elektroda merupakan konduktor yang digunakan untuk bersentuhan dengan bagian non-logam. Pada sel elektrolisa elektroda disebut sebagai anoda dan katoda. Anoda adalah elektroda positif yaitu elektron akan datang dari sel elektrolisa untuk terjadinya proses oksidasi. Katoda adalah elektroda negatif dimana elektron masuk ke sel elektrolisa sehingga terjadinya reduksi. Elektroda yang digunakan salah satunya adalah alumunium. Latar belakang digunakannya alumunium (Al) sebagai elektroda adalah karena Alumunium merupakan logam aktif dengan potensial elektroda lebih negatif daripada air yaitu elektroda alumunium $=-1,66$ dan elektrode air $=-0,83$.

\subsection{Mikrokontroler AVR ATMega 8535}

Mikrokontroler adalah perangkat elektronika digital dengan fitur masukan dan keluaran dan juga kendali yang diatur oleh program secara fleksibel dapat ditulis dan dihapus dengan cara khusus. Mikrokontroler bekerja secara sederhana adalah menulis dan membaca data. Mikrokontroler dapat disebut 
komputer dalam bentuk chip yang digunakan untuk kontrol piranti elektronik untuk menekan efisiensi dan efektifitas biaya.

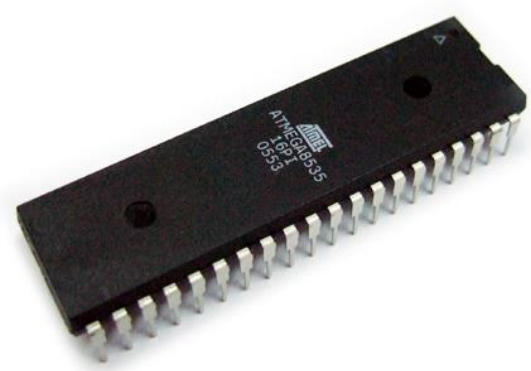

Gambar 1. Mikrokontroler ATMega 8535

Sumber : http://teknikinformatikaesti.blogspot.com/2011/04/mikrokontroler-avr-atmega8535.html

Kemampuan yang terdapat pada ATMega 8535 adalah mikrokontroler 8 bit dengan jumlah I/O sebanyak 32 buah yang terbagi menjadi 4 port yaitu A, B, C dan D. Piranti ini memiliki memori flash sebesar 8 $\mathrm{kb}$, dan EEPROM 512 byte. Meskipun ATMega 8535 merupakan teknologi mikro lama, namun piranti ini masih layak digunakan untuk kontrol sebuah sistem dengan harga murah.

\subsection{Liquid Crystal Display (LCD)}

LCD adalah piranti yang digunakan untuk menampilkan pesan yan terdapat pada alamat label LCD. sebagai keluaran waktu pada mikrokontroller ATmega 8535. LCD mempunyai banyak variasi ukuran, tapi dalam perancangan alat ini yang digunakan adalah LCD dengan ukuran 2x16 (dua baris enam belas kolom) LM162A. Yang perlu diperhatikan dalam hal ini adalah:

1. LCD selalu pada kondisi tulis (write) dengan menghubungkan kaki $\mathrm{R} / \mathrm{W}$ ke ground, agar LCD tidak mengeluarkan data atau kondisi baca (read).

2. Akses ke LCD dilakukan dengan menggunakan mode I/O biasa dan tidak menggunakan mode bus walaupun LCD terhubung jalur bus, berikut gambar LCD dapat dilihat pada gambar 2 berikut ini.

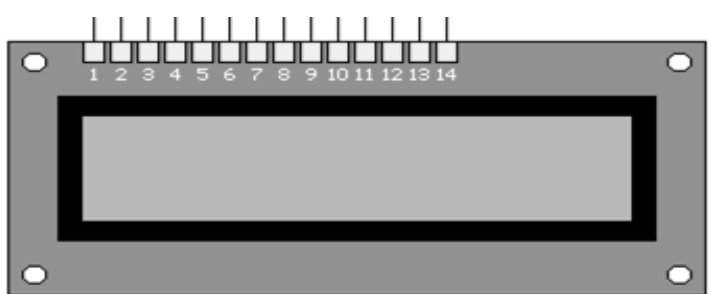

Gambar 2. LCD LMB162A

LCD display modul disusun dalam kontroler LSI, dimana kontrol mempunyai dua register 8 bit diantaranya IR (instruksi register) dan DR (data register). IR disimpan dengan kode instruksi, seperti display clear dan cusor shift, dan juga RAM dan CGRAM.

\section{HASIL DAN DISKUSI}

\subsection{Pembuatan Alat}

Secara umum pembuatan alat yang dirancang terdiri dari beberapa bagian, yaitu :

1. Mikrokontroller ATmega8535

Mikrokontroller ATmega8535 berfungsi untuk menerima data dan memberikan perintah terhadap rangkaian untuk menjalankan tugas atau perintah yang sudah didownload kedalam mikrokontroller ATmega8535 itu sendiri.

2. Aktuator (Motor DC)

Aktuator (Motor DC) berfungsi sebagai komponen yang menggerakkan mekanik agar dapat membuka dan menutup kran vakum guna untuk melewatkan gas $\mathrm{HHO}$ atau BBM.

\section{LCD (Liquid Crystal Display)}

LCD berfungsi sebagai komponen yang menampilkan pembacaan dari setiap sensor seperti RPM mesin,Kualitas air dan Volume BBM.

4. Sensor kualitas air

Berfungsi untuk mendeteksi kelayakan air dalam tabung.

\section{Sensor Volume BBM}

Berfungsi untuk mendeteksi volume bbm dalam tangki BBM. 
6. Sensor tegangan

Sensor tegangan disini memamfaatkan sistem pembagi tegangan dari tegangan sepull magnet yang ada di sepeda motor berdasarkan naik turunnya rpm mesin yang kemudian diselesaikan oleh rangkaian komparator yang diumpankan ke mikrokontroler.

\section{Rangkaian timer IC 555}

Berfungsi untuk memberikan waktu pada driver motor untuk membuka atau menutup kran vakum berdasarkan seting waktu tertentu.

\section{Power supply}

Catu daya Power Supply ini merupakan catu daya linier yang merupakan catu daya untuk mengubah tegangan $\mathrm{AC}$ menjadi tegangan DC.

\subsection{Analisa Hasil}

Setelah dilakukan perancangan keseluruhan sistem, maka dilakukan pengujian alat yang digunakan untuk mengetahui kinerja dan program yang telah disusun. Pengujian dilakukan dengan pembahasan perangkat keras, perangkat lunak dan keseluruhan sistem.

\section{Pengujian konsumsi BBM}

- Tujuan

Untuk mengtahui apakah ada perubahan konsumsi BBM dengan adanya penambahan alat pengirit bahan bakar tersebut maka di analisa berdasarkan jarak tempuh ( KM ).

- Peralatan yang digunakan

1. Sepeda motor.

2. Unit tabung elektroliser.

- Prosedur pengujian

1. Mengaplikasikan alat pengirit bahan bakar pada sepeda motor.

2. Melakukan tes uji coba dan berapa jarak tempuh yang diperoleh tanpa menggunakan alat pengirit BBM.

3. Melakukan tes uji coba dengan menambahkan alat pengirit BBM dan berapa jarak tempuh yang diperoleh.

4. Mengamati selisih jarak tempuh antara menggunakan alat pengirit BBM dengan tanpa menggunakan alat tersebut.

Tabel 1 Hasil percobaan konsumsi BBM.

\begin{tabular}{cccccc}
\hline No. & Tanggal & Uraian & $\begin{array}{c}\text { Konsumsi } \\
\text { BBM } \\
(\mathrm{L})\end{array}$ & $\begin{array}{c}\text { Jarak } \\
\text { tempuh } \\
(\mathrm{KM})\end{array}$ & Keterangan \\
\hline Konsumsi & & & Bekerja \\
1 & $\begin{array}{c}\text { januari } \\
2018\end{array}$ & $\begin{array}{c}\text { BBM } \\
\text { tanpa }\end{array}$ & 0.5 Liter & 26.9 & $\begin{array}{c}\text { dengan } \\
\text { baik }\end{array}$ \\
2 & $\begin{array}{c}\text { HHO } \\
\text { januari } \\
2018\end{array}$ & $\begin{array}{c}\text { Konsumsi } \\
\text { BBM + } \\
\text { HHO }\end{array}$ & 0.5 Liter & 41.2 & $\begin{array}{c}\text { Bekerja } \\
\text { dengan } \\
\text { baik }\end{array}$ \\
\hline
\end{tabular}

Dari data tabel yang didapatkan diatas, maka dapat disimpulkan bahwa alat telah berjalan baik sesuai dengan yang diharapkan. Dan pengiritan terjadi terbukti dari selisih jarak tempuh yang dihasilkan seperti terlihat pada tabel 1 .

2. Rangkaian Motor DC dan Kran otomatis Pengujian rangkaian Motor DC dan kran otomatis dilakukan dengan menghubungkan rangkaian Motor DC pada port Mikrokontroller ATmega8535 yang telah diprogram agar menghasilkan daya untuk menggerakkan Motor DC. Pengujian ini bertujuan untuk mengetahui bahwa Motor DC dan kran otomatis dapat bekerja dengan baik.

Tabel 2. Hasil Pengujian Motor DC dan buka tutup kran otomatis

\begin{tabular}{ccccc}
\hline No. & $\begin{array}{c}\text { Kondisi } \\
\text { Port }\end{array}$ & $\begin{array}{c}\text { Arah putar } \\
\text { motor DC }\end{array}$ & $\begin{array}{c}\text { Kondisi } \\
\text { Kran }\end{array}$ & Keterangan \\
\hline
\end{tabular}




\begin{tabular}{|c|c|c|c|c|}
\hline & & & - Kran & \\
\hline 1 & $\begin{array}{l}\text { PortD. } 3=1 \\
\text { PortD. } 4=0\end{array}$ & $\begin{array}{l}\text { Motor DC } \\
\text { berputar } \\
\text { searah } \\
\text { jarum jam }\end{array}$ & $\begin{array}{c}\text { BBM } \\
\text { Open } \\
\text { - Kran } \\
\text { HHO }\end{array}$ & $\begin{array}{c}\text { Bekerja } \\
\text { dengan } \\
\text { baik }\end{array}$ \\
\hline 2 & $\begin{array}{l}\text { PortD. } 3=0 \\
\text { PortD. } 4=1\end{array}$ & $\begin{array}{l}\text { Motor DC } \\
\text { berputar } \\
\text { berlawanan } \\
\text { jarum jam }\end{array}$ & $\begin{array}{c}\text { Close } \\
\text { - Kran } \\
\text { BBM } \\
\text { Close } \\
\text { - Kran } \\
\text { HHO } \\
\text { Open }\end{array}$ & $\begin{array}{c}\text { Bekerja } \\
\text { dengan } \\
\text { baik }\end{array}$ \\
\hline
\end{tabular}

Hasil pengujian motor :

Dari tabel diatas didapatkan data bahwa dalam proses pengujian Motor DC berjalan dengan baik, buka tutup kran otomatis berjalan sesuai dengan hasil yang diharapkan.

\section{Pengujian sensor kualitas air}

- Tujuan

Untuk mengtahui apakah sensor kualitas air dapat membaca perubahan kualitas air pada tabung elektroliser maka di analisa berdasarkan perubahan tegangan output dari sensor dengan merubah warna air menjadi kecoklatan sampai pada kondisi $25 \%$ dan air wajib diganti.

Tabel 3. Hasil Pengujian Sensor kualitas air.

\begin{tabular}{ccccc}
\hline No. & $\begin{array}{c}\text { Kondisi air } \\
\text { dalam tabung }\end{array}$ & $\begin{array}{c}\text { V } \\
\text { output } \\
\text { sensor }\end{array}$ & $\begin{array}{c}\text { Parameter } \\
\text { LCD } \\
\%\end{array}$ & Keterangan \\
\hline 1 & $\begin{array}{c}\text { Baru, } \\
\text { Bening/Jernih }\end{array}$ & $5 \mathrm{~V}$ & $99,9 \%$ & Baik \\
2 & $\begin{array}{c}\text { Agak } \\
\text { kecoklatan }\end{array}$ & $4 \mathrm{~V}$ & $75 \%$ & Baik \\
3 & $\begin{array}{c}\text { Air berwarna } \\
\text { coklat }\end{array}$ & $1 \mathrm{~V}$ & $25 \%$ & Ganti \\
\hline
\end{tabular}

4. Rangkaian Power Supply

- Tujuan

Memberikan tegangan sebesar $5 \mathrm{~V}$ dan

$12 \mathrm{~V}$ untuk rangkaian alat.

- Peralatan yang digunakan

1. Tegangan PLN ( 220V )

2. Rangkaian power supply.

- Prosedur pengujian
1. Merangkai rangkaian seperti pada skema.

2. Memberikan tegangan $220 \mathrm{~V}$ pada rangkaian power supply tersebut.

Tabel 4. Percobaan Power Supply

\begin{tabular}{|c|c|c|c|}
\hline No. & Rangkaian & $\begin{array}{c}\text { Tegangan } \\
\text { yang } \\
\text { diinginkan }\end{array}$ & Hasil \\
\hline 1 & $\begin{array}{l}\text { Mikrokontroller } \\
\text { ATmega8535 }\end{array}$ & $5 \mathrm{~V}$ & $+5 \mathrm{~V}$ \\
\hline 2 & Sensor BBM & $5 \mathrm{~V}$ & $+5 \mathrm{~V}$ \\
\hline 3 & Sensor Infrared & $5 \mathrm{~V}$ & $+5 \mathrm{~V}$ \\
\hline 4 & Motor DC & $12 \mathrm{~V}$ & $+12 \mathrm{~V}$ \\
\hline 5 & Tabung elektrolisa & $12 \mathrm{~V}$ & $+12 \mathrm{~V}$ \\
\hline
\end{tabular}

\section{KESIMPULAN}

Dari hasil pengujian dan analisis yang telah dilakukan, maka dapat ditarik kesimpulan sebagai berikut :

1. Alat bahan bakar air bekerja sesuai dengan yang diharapkan. Terbukti bahwa alat bahan bakar air dapat mengurangi konsumsi BBM dengan selisih jarak tempuh 14,3 KM / 0,5 liter setelah menggunakan alat bahan bakar air tersebut.

2. Kualitas air dalam tabung terkontrol kelayakannya terbukti dengan adanya perubahan tampilan persentase kualitas air pada layar LCD seiring dengan kurang maksimalnya gas yang dihasilkan.

3. Mekanik yang dirancang untuk system buka tutup kran otomatis dapat berjalan sesuai yang diinginkan.

4. Rangkaian driver pada motor bekerja dengan baik sehingga motor DC bergerak dengan gerakan sesuai yang diharapkan, dan alat dapat bekerja secara otomatis berdasarkan masukan dari sensor.

5. Pada pengujian tegangan didapati bahwa tegangan hasil perhitungan dan tegangan hasil pengukuran 
mempunyai sedikit perbedaan dengan rata-rata perbedaan $0.12 \mathrm{~V}$ yang berarti rangkaian keseluruhan bekerja dengan baik. .

\section{Daftar pustaka}

[1] Esculenta, Mira. 2017. "Sistem Elektrolisa Air Sebagai Bahan Bakar Alternatif Pada Kendaraan”. Jurnal ELTEK Vol. 12 No.1, April 2014 ISSN 1693-4024. Politeknik Negeri Malang. Malang.

[2] Muliawati, Neni. 2008. "Hidrogen Sebagai Sel Bahan Bakar : Sumber Energi Masa Depan. Makalah Kuliah Energi Terbarukan”. Universitas Lampung. Lampung

[3] Nofriyandi. 2016. Aplikasi Gas HHO Pada Sepeda Motor 150 CC. Buku Tugas Akhir. Intitut Teknologi Sepuluh Nopember. Surabaya.

[4] Megawati, Arman, Triyanto. 2016. Prototipe Alat Penjernih Air Sumur Otomatis Berbasis Mikrokontroler 8535. Coding Jurnal Komputer dan Aplikasi. Pontianak.

[5] Amani, Prawiroredjo. 2016. Alat Ukur Kualitas Air Minum Dengan Parameter PH, Suhu, Tingkat Kekeruhan, dan Jumlah Padatan Terlarut. JETRI : Jurnal Ilmiah Teknik Elektro. Jakarta 